\title{
Apitherapy Have a Role in Treatment of Multiple Sclerosis
}

\author{
Suzette I. Helal ${ }^{1 *}$, Ahmad Hegazi ${ }^{2}$, Khaled Al-Menabbawy ${ }^{3}$ \\ ${ }^{1}$ National Research Center - Research on Children with Special Needs Department, Giza, Egypt; ${ }^{2}$ National Research Center \\ - Child Health, Cairo, Egypt; ${ }^{3}$ National Research Center - Microbiology and Immunology, Cairo, Egypt
}

Citation: Helal SI, Hegazi A, Al-Menabbawy K Apitherapy Have a Role in Treatment of Multiple Sclerosis. OA Maced J Med Sci. 2014 Jun 15; 2(2):265-270.

http://dx.doi.org/10.3889/oamjms.2014.044

Key words: Apitherapy; Multiple Sclerosis; Bee venom; Food Supplements.

"Correspondence: Suzette Helal, Children with Special Needs Department, National Research Centre, El-Bohouth Street, Dokki, 2311, Cairo, Egypt. Fax: +202 3370931, Tel: 201001004562 . suzettehelal@yahoo.com

Received: 07-Apr-2014; Revised: 18-Apr2014; Accepted: 05-May-2014; Online first: 22-May-2014

Copyright: () 2014 Helal et al. This is an open access article distributed under the terms of the Creative Commons Attribution License, hhich permits and reproduction in any medium, provided the riginal author and sour are credited.

Competing Interests: The authors have declared that no competing interests exist.

\begin{abstract}
AIM: Multiple sclerosis (MS) is an inflammatory disease in which the fatty myelin sheaths around the axons of the brain and spinal cord are damaged. We Study the effect of Apitherapy in treatment of MS.

MATERIAL AND METHODS: Fifty patients with MS, their ages ranged between 26-71 years, were subjected to complete clinical and neurological history and examination to confirm the diagnosis. All cases were under their regular treatment they were divided into two main groups, Group I received honey, pollen, royal jelly and propolis and were treated with apiacupuncture 3 times weekly, for 12 months, in addition to their medical treatment, while group II remains on their ordinary medical treatment only. Apiacupuncture was done by bee stings for regulating the immune system.
\end{abstract}

RESULTS: Results revealed that 4 patients showed some improvement regarding their defects in gait, bowel control, constipation and urination, while 12 cases, showed some mild improvement in their movement in bed, and better improvement in bed sores, sensation, and better motor power, only two cases of them were able to stand for few minutes with support.

CONCLUSION: Although Apitherapy is not a curable therapy in MS, but it can be used to minimize the clinical symptoms of MS, and can be included among programs of MS therapy.

\section{Introduction}

Multiple sclerosis (MS) is an inflammatory disease in which the fatty myelin sheaths around the axons of the brain and spinal cord are damaged, leading to demyelination and scarring as well as a broad spectrum of signs and symptoms [1]. MS is an important problem both for people with the disease and for society. There is no cure, and alleviation of symptoms forms the cornerstone of care. Excessive fatigue that severely limits activity is experienced by at least two-thirds of the estimated 60,000 people with MS in the UK [2]. There is no known cure for multiple sclerosis. Treatments attempt to return function after an attack, prevent new attacks, and prevent disability [3]. MS medications can have adverse effects or be poorly tolerated, and many people pursue alternative treatments, despite the lack of supporting scientific study. The prognosis is difficult to predict; it depends on the subtype of the disease, the individual's disease characteristics, the initial symptoms and the degree of disability the person experiences as time advances [4,
5]. The primary aims of therapy are returning function after an attack, preventing new attacks, and preventing disability [6].

Apitherapy is the medical use of honey bee products. This can include the use of honey, pollen, bee bread, propolis, royal jelly, and apilarnil and bee venom. Most claims of apitherapy have not been proved to the scientific standards of evidencebased medicine and are anecdotal in nature. Bee venom therapy is an alternative form of healing. Bee venom therapy is the part of apitherapy which utilizes bee venom in the treatment of health conditions. However, bee venom is a complex mix of a variety of peptides and proteins, some of which have strong neurotoxic and immunogenic effects [7]. It has been used since ancient times to treat arthritis, rheumatism, back pain, skin diseases and in this modern age as an alternative therapy to treat autoimmune diseases, Lyme disease and chronic fatigue syndrome [8, 9]. Some reports have shown beneficial effects of bee venom in postherpetic neuralgia [10], swine flu [11], 
fibromyalgia and multiple sclerosis [12]. There is no standardized practice for the administration of bee venom.

Thus this study aimed to evaluate the role of apitherapy (bee venom, honey, pollen, royal jelly and propolis) among cases with MS.

\section{Material and Methods}

This study was carried on Fifty patients known to be with MS. Diagnosis was confirmed by clinical examination and radiological studies [13, 14]. Twelve males and thirty eight females, their ages ranged between 26-71 years, with a mean of $38.7 \pm 4.8$, two, from those attending the outpatient clinic of Adult Neurology in National Research Centre, Dokki, Egypt," over a period of three years from September 2008 till April 2011. All cases were subjected to complete clinical and neurological history and examination to confirm the diagnosis. There were 32 cases with quadriparesis, (8 males and 24 female) and 18 cases with paraparesis ( 4 males and 14 females). All cases were under their regular treatment either by corticosteroids, or interferon. These cases were divided into two main groups, each group consists of 25 cases ( 6 males and 19 females), Group I received honey, pollen, royal jelly and propolis and were treated with bee stings 3 times weekly, for 12 months, started gradually by one sting then gradually increase up to 25 stings per session - "after sensitivity test was done" - in addition to their medical treatment, while group II remains on their ordinary medical treatment only. Informed consent was signed by the patients and their caregivers to participate in the study including the following:

Full general and neurological assessment, including full history and examination according to sheet prepared for the study, neurological examination on the beginning of the study to confirm the diagnosis then examination was repeated every two months to examine and detect the changes which may be happened for each case, and recorded in the form of scores starting from 0 for normal with no abnormal signs up to 5 for complete disability.

Assessment parameters: General condition, depression, no energy fatigue, sleeping, heat tolerance, attention span, memory, rigidity, spasms and tremors were evaluated by scoring from 1 up 7 , the condition scores starting from 1 for normal with no abnormal signs up to 7 for bad by asking the patient and devalued during diagnosis.

Apiacupuncture done by bee stings in the following points $\mathrm{Du}$ 13, 14, Li 11, S6, S9, points for cervical area and lumber area and vision points GB2 and Li3 [15].

Supplementation: All patients of both groups were ordered to receive $50 \mathrm{gm}$ twice daily. For $100 \mathrm{~g}$, (roughly 5 tbsp) is composed of Energy $1,272 \mathrm{~kJ}$ (304 kcal), Carbohydrates $82.4 \mathrm{~g}$, Sugars $82.12 \mathrm{~g}$, Dietary fiber $0.2 \mathrm{~g}$, Fat $0 \mathrm{~g}$, Protein $0.3 \mathrm{~g}$, Water 17.10 g, Riboflavin (vit. $\mathrm{B}_{2}$ ) 0.038 mg (3\%), Niacin (vit. $\mathrm{B}_{3}$ ) $0.121 \mathrm{mg}(1 \%)$, Pantothenic acid $\left(\mathrm{B}_{5}\right) 0.068 \mathrm{mg}(1 \%)$, Vitamin $\mathrm{B}_{6} 0.024 \mathrm{mg}(2 \%)$, Folate (vit. $\left.\mathrm{B}_{9}\right) 2 \mu \mathrm{g}(1 \%)$, Vitamin C $0.5 \mathrm{mg}(1 \%)$, Calcium $6 \mathrm{mg}(1 \%)$, Iron 0.42 $\mathrm{mg}(3 \%)$, Magnesium $2 \mathrm{mg}$ (1\%), Phosphorus $4 \mathrm{mg}$ (1\%), Potassium 52 mg (1\%), Sodium 4 mg (0\%), Zinc $0.22 \mathrm{mg}(2 \%)[16]$.

Laboratory studies: Three milliliters of fasting venous blood were drawn with a sterile plastic syringe from each case and control. One milliliter of the blood was gently placed in a dry clean plastic tube containing EDTA as a blood anticoagulant for the estimation of blood $\mathrm{Hb}$ concentration, using cyanomethe-hemoglobin method according to the procedure described by Betke and Savelsberg, 1950 using Drabkin's solution as a diluent [17]. The rest $2 \mathrm{ml}$. blood were gently placed in a dry clean plastic tube and left for 15 minutes to clot then centrifuged at $3500 \mathrm{rpm}$ for separation of serum, which then kept in deep freeze at $-70^{\circ} \mathrm{C}$ until analysis for estimation of serum levels of calcium, zinc, copper, vitamin $\mathrm{E}$ and Folat. All these investigations were done at the beginning of the study and by the end of one year of supplementation and bee sting sessions.

Statistical analysis: All data obtained were statistically analyzed using Microsoft Excel and SPSS 11.5 for windows software package including, "t test, non-parametric Qui square, Mann witney and anova test" as (Steel and Torrie, 1980) [18].

\section{Results}

In this study were included fifty patients diagnosed as MS, twelve males and thirty eight females, their ages ranged between $26-71$ years, with a mean of $38.7 \pm 4.8$. Thirty two cases with quadriparesis, ( 8 males and 24 female) and 18 cases with paraparesis (4 males and 14 females). During the period of the study there was gradual assessment of signs and symptoms every 2 months for both groups of patients. This periodic assessment for both groups showed the improvement in the scores of signs recorded every two months as shown in Table (1\& 2). Results revealed that 4 patients out of $9(44.4 \%$ of paraparesis cases), showed significant improvement regarding their defects in gait, bowel control, constipation and urination, while 12 cases out of 16 cases (75\% of quadriparesis cases), showed mild improvement in their movement in bed, and better improvement in bed sores, sensation, and better motor power, only two cases of them (12.5\%) were able to stand for few minutes with support among patients of group I. Also Fig. 1 showed mild improvement. 
Table 1: Scores of signs recorded every two months (1-12), for patients of group (I).

\begin{tabular}{|c|c|c|c|c|c|c|}
\hline Months & 2 Months & 4 Months & 6 Months & 8 Months & 10 Months & 12 Months \\
\hline General Condition & $4.87 \pm 0.440$ & $4.57 \pm 0.278$ & $3.87 \pm 0.398$ & $3.71 \pm 0.267$ & $2.85 \pm 0.243$ & $2.37 \pm 0.182$ \\
\hline Depression & $3.50 \pm 0.707$ & $3.62 \pm 0.625$ & $3.37 \pm 0.652$ & $3.00 \pm 0.534$ & $2.62 \pm 0.323$ & $1.75 \pm 0.25$ \\
\hline No Energy Fatigue & $3.75 \pm 0.647$ & $3.37 \pm 0.595$ & $3.62 \pm 0.893$ & $4.25 \pm 0.883$ & $2.87 \pm 0.665$ & $2.75 \pm 0.311$ \\
\hline Sleeping & $3.75 \pm 0.490$ & $3.37 \pm 0.679$ & $2.50 \pm 0.327$ & $2.37 \pm 0.323$ & $1.75 \pm 0.25$ & $1.37 \pm 0.182$ \\
\hline Heat tolerance & $3.75 \pm 0.725$ & $3.37 \pm 0.818$ & $2.50 \pm 0.590$ & $2.37 \pm 0.534$ & $1.75 \pm 0.462$ & $1.37 \pm 0.365$ \\
\hline Attention span & $2.12 \pm 0.479$ & $2.00 \pm 0.534$ & $1.87 \pm 0.398$ & $1.50 \pm 0.267$ & $1.25 \pm 0.163$ & $1.25 \pm 0.163$ \\
\hline Memory & $2.12 \pm 0.350$ & $2.00 \pm 0.462$ & $1.75 \pm 0.365$ & $1.50 \pm 0.188$ & $1.62 \pm 0.182$ & $1.50 \pm 0.188$ \\
\hline Rigidity & $2.50 \pm 0.50$ & $2.50 \pm 0.654$ & $3.00 \pm 0.731$ & $2.25 \pm 0.411$ & $2.12 \pm 0.479$ & $1.62 \pm 0.323$ \\
\hline Spasms & $2.37 \pm 0.595$ & $1.87 \pm 0.610$ & $2.50 \pm 0.462$ & $1.75 \pm 0.313$ & $2.50 \pm 0.707$ & $1.87 \pm 0.398$ \\
\hline Tremors & $2.37 \pm 0.32$ & $2.50 \pm 0.654$ & $2.75 \pm 0.674$ & $2.25 \pm 0.453$ & $2.37 \pm 0.679$ & $2.01 \pm 0.15$ \\
\hline Headaches & $1.87 \pm 0.639$ & $2.62 \pm 0.625$ & $2.12 \pm 0.398$ & $1.62 \pm 0.263$ & $1.75 \pm 0.313$ & $1.37 \pm 0.263$ \\
\hline Eye sight & $2.50 \pm 0.566$ & $2.50 \pm 0.566$ & $2.25 \pm 0.490$ & $1.87 \pm 0.440$ & $1.87 \pm 0.398$ & $1.75 \pm 0.313$ \\
\hline Speech & $1.62 \pm 0.263$ & $1.62 \pm 0.263$ & $1.87 \pm 0.295$ & $1.50 \pm 0.267$ & $1.50 \pm 0.267$ & $1.37 \pm 0.182$ \\
\hline Swallowing & $1.37 \pm 0.263$ & $1.37 \pm 0.182$ & $1.37 \pm 0.182$ & $1.12 \pm 0.125$ & $1.25 \pm 0.163$ & $1.12 \pm 0.125$ \\
\hline Numbness & $2.62 \pm 0.375$ & $2.62 \pm 0.375$ & $2.25 \pm 0.453$ & $1.87 \pm 0.295$ & $1.62 \pm 0.375$ & $1.25 \pm 0.163$ \\
\hline Balance & $4.62 \pm 0.800$ & $3.87 \pm 0.685$ & $3.00 \pm 0.843$ & $2.50 \pm 0.707$ & $1.87 \pm 0.692$ & $1.50 \pm 0.834$ \\
\hline Walking & $4.37 \pm 0.595$ & $4.37 \pm 0.595$ & $4.50 \pm 0.707$ & $4.25 \pm 0.75$ & $3.87 \pm 0.742$ & $2.87 \pm 0.639$ \\
\hline Hand coordination & $2.62 \pm 0.532$ & $2.62 \pm 0.460$ & $1.87 \pm 0.226$ & $1.75 \pm 0.25$ & $1.50 \pm 0.188$ & $1.37 \pm 0.182$ \\
\hline Writing & $2.62 \pm 0.679$ & $2.87 \pm 0.789$ & $2.12 \pm 0.548$ & $1.87 \pm 0.479$ & $1.75 \pm 0.365$ & $1.62 \pm 0.263$ \\
\hline Bladder \& Bowel & $4.12 \pm 0.580$ & $4.12 \pm 0.580$ & $3.50 \pm 0.597$ & $3.25 \pm 0.526$ & $2.37 \pm 0.323$ & $2.12 \pm 0.226$ \\
\hline
\end{tabular}

As shown in Table 3, the scores of symptoms recorded at start and the end of the investigation among patients for both groups. There was no statistical significant differences between group I and group II at the start of the study, regarding their general condition, depression, fatigue, sleeping heat tolerance, attention span, memory, rigidity, spasms and tremors, while by the end of the study there were significant improvement regarding general condition, depression sleeping, heat tolerance attention span, memory as well as rigidity and muscle spasms.

Table 4 shows the comparison between the mean plasma and serum concentrations of micronutrients for both groups of MS at the start and end of the study. There were no statistical significant differences between group I and group II at the start of the study, regarding their mean plasma and serum concentrations of micronutrients for both groups of MS at the start and end of the study.

\section{Discussion}

MS affects the ability of nerve cells in the brain and spinal cord to communicate with each other effectively [3]. Theories include genetics or infections. Different environmental risk factors have also been found [19]. Life expectancy of people with MS is 5 to 10 years lower than that of the unaffected population
[1]. Several subtypes, or patterns of progression, have been described. Subtypes use the past course of the disease in an attempt to predict the future course. They are important not only for prognosis but also for therapeutic decisions [5]. Although there is no known cure for multiple sclerosis, several therapies have proven helpful.

Bee sting therapy is increasingly used to treat patients with multiple sclerosis (MS) in the belief that it can stabilize or ameliorate the disease. However, there are no clinical studies to justify its use. Wesselius et al, 2005 found that there was no improvement of disability, fatigue, and quality of life [20]. Bee sting therapy was well tolerated, and there were no serious adverse events. They concluded that the treatment with bee venom in patients with relapsing multiple sclerosis did not reduce disease activity, disability, or fatigue and did not improve quality of life.

The therapeutic benefits of honeybee venom have been known for a long time to relieve pain and to treat inflammatory diseases particularly for treatment of arthritic and rheumatic conditions in humans [21, 22] and in animals [23-25]. Specific immunotherapy with bee venom can result in an almost complete protection against adverse (or allergic) reactions from stings in the great majority of cases [26].

Table 2: Scores of signs recorded every two months (1-12), for patients of group (II).

\begin{tabular}{|c|c|c|c|c|c|c|}
\hline Months & 2 Months & 4 Months & 6 Months & 8 Months & 10 Months & 12 Months \\
\hline General Condition & $3.73 \pm 0.5$ & $3.49 \pm 0.26$ & $3.17 \pm 0.23$ & $3.01 \pm 0.22$ & $2.83 \pm 0.13$ & $2.8 \pm 0.12$ \\
\hline Depression & $3.62 \pm 0.24$ & $3.6 \pm 0.35$ & $3.29 \pm 0.12$ & $3.05 \pm 0.72$ & $2.76 \pm 0.45$ & $2.45 \pm 0.33$ \\
\hline No Energy Fatigue & $3.24 \pm 0.6$ & $3.25 \pm 0.35$ & $3.24 \pm 0.38$ & $3.28 \pm 0.28$ & $2.95 \pm 0.85$ & $2.85 \pm 0.35$ \\
\hline Sleeping & $3.4 \pm 0.58$ & $3.39 \pm 0.46$ & $3.07 \pm 0.12$ & $2.8 \pm 0.62$ & $2.35 \pm 0.25$ & $2.07 \pm 0.12$ \\
\hline Heat tolerance & $3.5 \pm 0.75$ & $3.39 \pm 0.16$ & $3.06 \pm 0.590$ & $2.73 \pm 0.63$ & $2.5 \pm 0.42$ & $2.37 \pm 0.365$ \\
\hline Attention span & $2.1 \pm 0.45$ & $2.06 \pm 0.32$ & $1.93 \pm 0.66$ & $1.67 \pm 0.21$ & $1.53 \pm 0.62$ & $1.38 \pm 0.22$ \\
\hline Memory & $2.3 \pm 0.35$ & $2.13 \pm 0.27$ & $2.05 \pm 0.05$ & $1.92 \pm 0.27$ & $1.82 \pm 0.15$ & $1.72 \pm 0.13$ \\
\hline Rigidity & $2.48 \pm 0.52$ & $2.39 \pm 0.52$ & $2.17 \pm 0.33$ & $2.06 \pm 0.18$ & $1.92 \pm 0.72$ & $1.84 \pm 0.23$ \\
\hline Spasms & $2.4 \pm 0.58$ & $2.26 \pm 0.19$ & $2.19 \pm 0.25$ & $2.03 \pm 0.18$ & $1.89 \pm 0.09$ & $1.74 \pm 0.398$ \\
\hline Tremors & $2.36 \pm 0.43$ & $2.3 \pm 0.52$ & $2.28 \pm 0.45$ & $2.2 \pm 0.32$ & $2.17 \pm 0.66$ & $2.12 \pm 0.718$ \\
\hline Headaches & $1.86 \pm 0.19$ & $1.72 \pm 0.23$ & $1.66 \pm 0.32$ & $1.59 \pm 0.28$ & $1.49 \pm 0.19$ & $1.42 \pm 0.23$ \\
\hline Eye sight & $2.48 \pm 0.36$ & $2.39 \pm 0.34$ & $2.31 \pm 0.09$ & $2.27 \pm 0.62$ & $2.13 \pm 0.18$ & $2.01 \pm 0.13$ \\
\hline Speech & $1.59 \pm 0.63$ & $1.55 \pm 0.17$ & $1.49 \pm 0.24$ & $1.44 \pm 0.15$ & $1.4 \pm 0.28$ & $1.37 \pm 0.08$ \\
\hline Swallowing & $1.45 \pm 0.21$ & $1.41 \pm 0.22$ & $1.38 \pm 0.42$ & $1.32 \pm 0.19$ & $1.29 \pm 0.33$ & $1.26+0.25$ \\
\hline Numbness & $2.5 \pm 0.5$ & $2.42 \pm 0.34$ & $2.23 \pm 0.66$ & $2.07 \pm 0.35$ & $1.91 \pm 0.07$ & $1.72 \pm 0.12$ \\
\hline Balance & $3.49 \pm 0.26$ & $3.37 \pm 0.63$ & $3.02 \pm 0.42$ & $2.71 \pm 0.17$ & $2.47 \pm 0.32$ & $2.05 \pm 0.47$ \\
\hline Walking & $3.3 \pm 0.62$ & $3.27 \pm 0.25$ & $3.14 \pm 0.45$ & $3.07 \pm 0.37$ & $2.96 \pm 0.52$ & $2.87 \pm 0.639$ \\
\hline Hand coordination & $2.7 \pm 0.28$ & $2.6 \pm 0.34$ & $2.47 \pm 0.56$ & $2.35 \pm 0.77$ & $2.19 \pm 0.28$ & $2.04 \pm 0.12$ \\
\hline Writing & $2.65 \pm 0.25$ & $2.57 \pm 0.09$ & $2.42 \pm 0.52$ & $2.31 \pm 0.08$ & $2.18 \pm 0.33$ & $2.02 \pm 0.26$ \\
\hline Bladder \& Bowel & $3.09 \pm 0.35$ & $2.96 \pm 0.65$ & $2.83 \pm 0.42$ & $2.79 \pm 0.67$ & $2.69 \pm 0.44$ & $2.63 \pm 0.16$ \\
\hline
\end{tabular}


In our study we found that there is a statistically significant improvement regarding their immunity and the improvement in their health and general conditions and this is explained by [27, 28], that Bee stings cause hemoconcentration which might be related to the marked edema induced by the venom. Following bee stings there is an increase in various cytokines like interleukin (IL)-1 1 , IL-6, tumor necrosis factor- $\alpha$, etc. In a mouse model using the subcutaneous route, rapid increases in serum alanine aminotransferase and aspartate aminotransferase transaminases, creatinine, urea nitrogen, uric acid, sodium and chloride electrolytes, and creatine kinase were recorded [27, 28].

Table 3: Comparison between patients of group I \& group II regarding the signs at the start and end of the study.

\begin{tabular}{|c|c|c|c|c|c|c|}
\hline \multirow[b]{2}{*}{ Clinical signs } & \multicolumn{2}{|c|}{ Mean \pm SE of signs at the start of the study } & \multicolumn{4}{|c|}{ Mean \pm SE of signs at the end of the } \\
\hline & $\begin{array}{l}\text { Group I } \\
(n=25)\end{array}$ & $\begin{array}{c}\text { Group II } \\
(n=25)\end{array}$ & $P$ - value & $\begin{array}{l}\text { Group I } \\
(n=25)\end{array}$ & $\begin{array}{c}\text { Group II } \\
(n=25)\end{array}$ & $P$ - value \\
\hline General Condition & $4.87 \pm 0.440$ & $3.73 \pm 0.5$ & 0.06 & $2.37 \pm 0.182$ & $2.8 \pm 0.12$ & 0.05 \\
\hline Depression & $3.5 \pm 0.707$ & $3.62 \pm 0.24$ & 0.1 & $1.75 \pm 0.25$ & $2.45 \pm 0.33$ & 0.004 \\
\hline No Energy Fatigue & $3.75 \pm 0.647$ & $3.24 \pm 0.6$ & 0.05 & $2.75 \pm 0.311$ & $2.85 \pm 0.35$ & 0.04 \\
\hline Sleeping & $3.75 \pm 0.49$ & $3.4 \pm 0.58$ & 0.07 & $1.37 \pm 0.182$ & $2.07 \pm 0.12$ & 0.003 \\
\hline Heat tolerance & $3.75 \pm 0.725$ & $3.5 \pm 0.75$ & 0.05 & $1.37 \pm 0.365$ & $2.37 \pm 0.365$ & 0.005 \\
\hline Attention span & $2.12 \pm 0.479$ & $2.1 \pm 0.45$ & 0.2 & $1.25 \pm 0.163$ & $1.38 \pm 0.22$ & 0.04 \\
\hline Memory & $2.12 \pm 0.350$ & $2.3 \pm 0.35$ & 0.1 & $1.50 \pm 0.188$ & $1.72 \pm 0.13$ & 0.02 \\
\hline Rigidity & $2.5 \pm 0.5$ & $2.48 \pm 0.52$ & 0.2 & $1.62 \pm 0.323$ & $1.84 \pm 0.23$ & 0.05 \\
\hline Spasms & $2.37 \pm 0.595$ & $2.4 \pm 0.58$ & 0.3 & $1.87 \pm 0.398$ & $1.74 \pm 0.398$ & 0.05 \\
\hline Tremors & $2.37 \pm 0.32$ & $2.36 \pm 0.43$ & 0.5 & $2.01 \pm 0.15$ & $2.12 \pm 0.718$ & 0.1 \\
\hline Headaches & $1.87 \pm 0.639$ & $1.86 \pm 0.19$ & 0.02 & $1.37 \pm 0.263$ & $1.42 \pm 0.23$ & 0.02 \\
\hline Eye sight & $2.50 \pm 0.566$ & $2.48 \pm 0.36$ & 0.005 & $1.75 \pm 0.313$ & $2.01 \pm 0.13$ & 0.005 \\
\hline Speech & $1.62 \pm 0.263$ & $1.59 \pm 0.63$ & 0.04 & $1.37 \pm 0.182$ & $1.37 \pm 0.08$ & 0.04 \\
\hline Swallowing & $1.37 \pm 0.263$ & $1.45 \pm 0.21$ & 0.05 & $1.12+0.125$ & $1.26+0.25$ & 0.05 \\
\hline Numbness & $2.62 \pm 0.375$ & $2.5 \pm 0.5$ & 0.05 & $1.25 \pm 0.163$ & $1.72 \pm 0.12$ & 0.05 \\
\hline Balance & $4.62 \pm 0.800$ & $3.49 \pm 0.26$ & 0.005 & $1.50 \pm 0.834$ & $2.05 \pm 0.47$ & 0.005 \\
\hline Walking & $4.37 \pm 0.595$ & $3.3 \pm 0.62$ & 0.04 & $2.87 \pm 0.639$ & $2.87 \pm 0.639$ & 0.04 \\
\hline Hand coordination & $2.62 \pm 0.532$ & $2.7 \pm 0.28$ & 0.005 & $1.37 \pm 0.182$ & $2.04 \pm 0.12$ & 0.02 \\
\hline Writing & $2.62 \pm 0.679$ & $2.65 \pm 0.25$ & 0.04 & $1.62 \pm 0.263$ & $2.02 \pm 0.26$ & 0.005 \\
\hline Bladder \& Bowel & $4.12 \pm 0.580$ & $3.09 \pm 0.35$ & 0.05 & $2.12 \pm 0.226$ & $2.63 \pm 0.16$ & 0.04 \\
\hline
\end{tabular}

According to Janik et al, 2007 [10], course of treatment starts with testing the patient for allergy, which is known to occur in $1 \%$ of the general population. Bee venom is administered in the form of a direct bee sting or else by injection of a venom extract, the treatment is usually given twice a week, this is agreed with our study we tested the patients for allergy, and we used the direct bee sting twice weekly for 6 months for each patients.

Bee venom acupuncture (BVA), as a kind of herbal acupuncture, exerts not only pharmacological actions from the bioactive compounds isolated from bee venom but also a mechanical function from acupuncture stimulation. BVA is growing in popularity, especially in Korea, and is used primarily for pain relief in many kinds of diseases [29].

We used Bee venom therapy for patients with MS and this is agreed with Park et al., 2010 and Prado et al., 2010, they stated that Bee venom therapy is used by people with many different autoimmune disorders, including MS, rheumatoid arthritis, lupus and scleroderma. It is also used for a number of other diseases and conditions, including depression, skin conditions, menstrual cramps and varicose veins $[27,28]$. It is claimed that bee venom therapy works with the patient's own body to reduce inflammation. The theory is that because the stings produce inflammation, the body mounts an antiinflammatory response. Presumably, this would then work to reduce inflammation where the myelin is being attacked by the immune system in a person with MS $[27,28]$

The location of the sting is important, with the sting acting as a sort of acupuncture in combination with the effects of the venom, while others report the location is not important. The number of stings also varies widely from a few to hundreds and they may be administered either by live bees or by injection. This treatment can cause pain, and even result in death if the subject has an allergy to bee venom, which can produce anaphylactic shock [20]. For honeybee venom subcutaneous immunotherapy 100 or $200 \mu \mathrm{g}$ doses are considered effective.

Table 4: Shows the comparison between the mean plasma and serum concentrations of micronutrients for both groups of MS at the start and end of the study.

\begin{tabular}{|c|c|c|c|c|c|c|}
\hline \multirow[b]{2}{*}{ Nutrient Level } & \multicolumn{2}{|c|}{$\begin{array}{l}\text { Mean } \pm \text { SE of plasma concentration among } \\
\text { cases at the start of the study }\end{array}$} & \multirow[b]{2}{*}{$P$ - value } & \multicolumn{2}{|c|}{$\begin{array}{l}\text { Mean } \pm \text { SE of plasma concentration among } \\
\text { cases at the end of the study }\end{array}$} & \multirow{2}{*}{$P$ - value } \\
\hline & $\begin{array}{l}\text { Group I } \\
(n=25)\end{array}$ & $\begin{array}{l}\text { Group II } \\
(n=25)\end{array}$ & & $\begin{array}{l}\text { Group I } \\
(n=25)\end{array}$ & $\begin{array}{l}\text { Group II } \\
(n=25)\end{array}$ & \\
\hline Iron $(\mu \mathrm{mol} / \mathrm{l})$ & $9.26 \pm 3.2$ & $9.14 \pm 1.7$ & 0.1 & $12.1 \pm 0.9$ & $10.6 \pm 1.4$ & 0.02 \\
\hline Calcium ( mg/dl ) & $1.83 \pm 0.04$ & $1.85 \pm 0.02$ & 0.12 & $2.09 \pm 0.02$ & $1.9 \pm 0.04$ & 0.005 \\
\hline Zinc $(\mu \mathrm{g} / \mathrm{dl})$ & $14.2 \pm 1.3$ & $13.9 \pm 1.5$ & 0.06 & $16.7 \pm 2.03$ & $14.1 \pm 2.02$ & 0.04 \\
\hline Copper $(\mu \mathrm{g} / \mathrm{dl})$ & $17.9 \pm 3.4$ & $18.1 \pm 2.6$ & 0.07 & $20.05 \pm 0.6$ & $18.9 \pm 1.9$ & 0.05 \\
\hline Vit. E (mg/dl) & $20.8 \pm 3.5$ & $21.1 \pm 2.8$ & 0.1 & $23.9 \pm 2.6$ & $22.3 \pm 2.4$ & 0.05 \\
\hline Folate $(\mathrm{nmcl} / \mathrm{l})$ & $32.2 \pm 2.7$ & $31.9 \pm 7.8$ & 0.3 & $49.6 \pm 6.4$ & $34.6 \pm 5.9$ & 0.005 \\
\hline Magnesium ( $\mathrm{mmol} / \mathrm{l}$ ) & $0.64 \pm 0.05$ & $0.65 \pm 0.02$ & 0.05 & $1.04 \pm 0.03$ & $0.98 \pm 0.04$ & 0.04 \\
\hline
\end{tabular}


The median lethal dose (LD50) for honeybee venom has been reported in a number of reports [30, 31] as $2.8 \mathrm{mg}$ venom $/ \mathrm{kg}$ body weight for intravenous and $3.8 \mathrm{mg}$ venom $/ \mathrm{kg}$ body weight for intraperitonealy delivery in mice.

A 2004 randomized crossover study was conducted in the Netherlands among 24 people with either relapsing-remitting MS or secondary- progressive MS. While the treatment was well-

tolerated, no beneficial effects were seen on the MRIs or clinically among these patients $[3,5]$. In our study there was a statistical significant improvement regarding the clinical findings while results of MRIs done for follow up for our patients showed that there is no more changes in the demyelinating lesions which means that demyelination shows no progression.

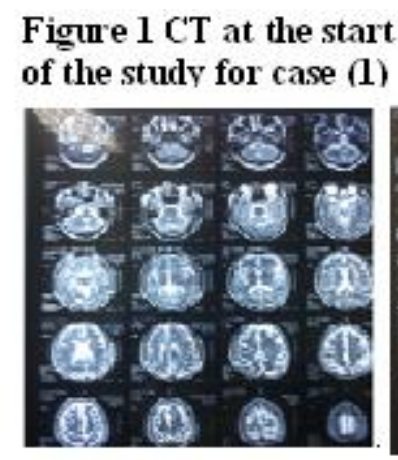

Figure $1 \mathrm{CT}$ at the end of the study for case (1)

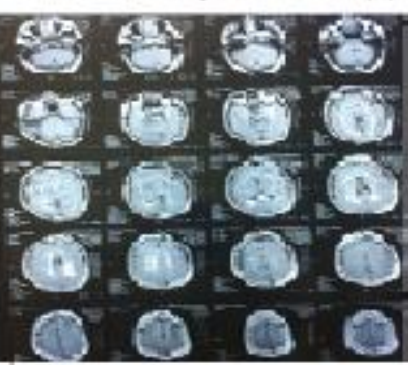

Figure 1 CT at the start of the study for case (2)

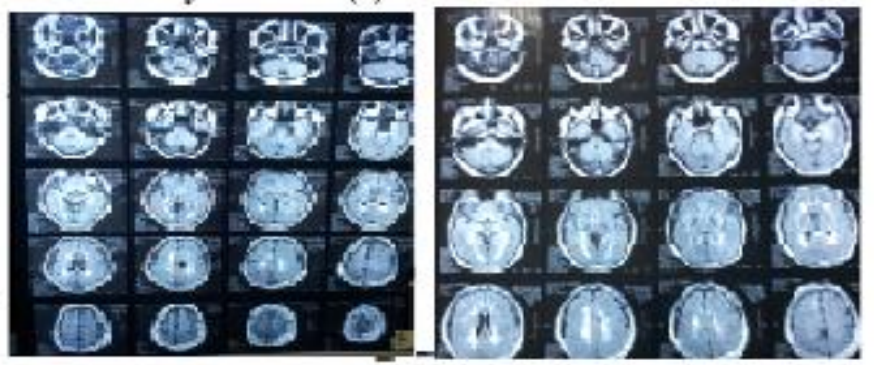

Fig. 1 showed CT at the start and by the end of the study.

Despite a lack of scientific evidence, bee venom therapy has been reported by people with MS to increase stability, as well as reduce fatigue and spasticity. More than 1,300 people with MS have sent testimonials to the American Apitherapy Society in support of the therapy [3], this is agreed by our study as patients under bee venom therapy showed marked improvement in stature, stability, and spasticity, While our study is disagreed with Castro et al, 2005 [7] they found that there were no definite conclusions regarding efficacy and therefore there was little evidence to support the use of honeybee venom in the treatment of MS. Larger and more carefully conducted multicenter studies will be required to establish efficacy.

In conclusion, although Apitherapy is not a curable therapy in MS, but it can be used to minimize the clinical symptoms of MS, and can be included among programs of MS therapy.

\section{Acknowledgment}

Many thanks for Prof. Dr. Iman Refaat and David Fakhry from the department of Medical Biochemistry in NRC.

\section{References}

1. Compston A, Coles A. Multiple sclerosis. Lancet. 2008;372(9648):1502-17.

2. Brañas $P$, Jordan R, Fry-Smith A, Burls A, Hyde C. Treatments for fatigue in multiple sclerosis: a rapid and systematic review. Health Technol Assess. 2000;4(27):1-61.

3. Compston A, Coles A. Multiple sclerosis. Lancet. 2002 Apr 6;359(9313):1221-31. Review. Erratum in: Lancet 2002;360(9333):648.

4. Weinshenker BG. Natural history of multiple sclerosis. Ann Neurol. 1994;36 Suppl:S6-11.

5. Lublin FD, Reingold SC. Defining the clinical course of multiple sclerosis: results of an international survey. National Multiple Sclerosis Society (USA) Advisory Committee on Clinical Trials of New Agents in Multiple Sclerosis. Neurology. 1996;46(4):907-11.

6. Feinstein A. The clinical neuropsychiatry of multiple sclerosis (2nd ed. ed.). Cambridge: Cambridge University Press, 2007: p. 20.

7. Castro HJ, Mendez-Lnocencio JI, Omidvar B, Omidvar J, Santilli J, Nielsen HS Jr, Pavot AP, Richert JR, Bellanti JA. A phase I study of the safety of honeybee venom extract as a possible treatment for patients with progressive forms of multiple sclerosis. Allergy Asthma Proc. 2005;26(6):470-6.

8. Hegazi AG. Medical importance of bee products. ARI BíLiMi / BEE SCIENCE. 2013; 12(4): 136-146.

9. Hegazi AG. Propolis an over view. J. Bee Informed. 1998; 5:5,22 -23; 6:723-28.

10. Janik JE, Wania-Galicia L, Kalauokalani D. Bee stings--a remedy for postherpetic neuralgia? A case report. Reg Anesth Pain Med. 2007;32(6):533-5.

11. Singla RK, Bhat VG. Honey bee sting and venom offering active as well as passive immunization could reduce swine flu pandemic A (H1N1). Med Hypotheses. 2010;74(3):617-8.

12. Alqutub A, Masoodi I, Alsayari K, Alomair A. Bee sting therapy-induced hepatotoxicity: A case report. World J Hepatol. 2011;3(10): 268-270.

13. Swanton JK, Rovira A, Tintore M, Altmann DR, Barkhof F, 
Filippi M, Huerga E, Miszkiel KA, Plant GT, Polman C, Rovaris M, Thompson AJ, Montalban X, Miller DH. MRI criteria for multiple sclerosis in patients presenting with clinically isolated syndromes: a multicentre retrospective study. Lancet Neurol. 2007;6(8):677-86.

14. Ebers GC, Kukay K, Bulman DE, Sadovnick AD, Rice G, Anderson C, Armstrong H, Cousin K, Bell RB, Hader W, Paty DW, Hashimoto S, Oger J, Duquette $P$, Warren S, Gray T, O'Connor P, Nath A, Auty A, Metz L, Francis G, Paulseth JE, Murray TJ, Pryse-Phillips W, Nelson R, Freedman M, Brunet D, Bouchard JP, Hinds D, Risch N. A full genome search in multiple sclerosis. Nat Genet. 1996;13(4):472-6.

15. Wagner P. Buttocks Jiagi Points Book, 1998.

16. Bowling AC, Stewart TM. Current complementary and alternative therapies of multiple sclerosis. Curr Treatment Options Neurol. 2003;5:55-68.

17. Betke K, Savelsberg W. Stulenphoto metrische hemoglobin best immuny mittles cyanohemoglobin 2. Biochemistry. 1950; 230: 431.

18. Steel RGD, Torrie JH. Principles and Procedures of Statistics 2nd ed. McGraw Hill Book Company: New York, 1980.

19. Ascherio A, Munger KL. Environmental risk factors for multiple sclerosis. Part I: the role of infection. Ann Neurol. 2007;61(4):288-99.

20. Wesselius T, Heersema DJ, Mostert JP, Heerings $M$, Admiraal-Behloul F, Talebian A, van Buchem MA, De Keyser J. A randomized crossover study of bee sting therapy for multiple sclerosis. Neurology. 2005;65(11):1764-8.

21. Pimenta AM, De Lima ME. Small peptides, big world: biotechnological potential in neglected bioactive peptides from arthropod venoms. J Pept Sci. 2005;11(11):670-6.

22. Goggs R, Vaughan-Thomas A, Clegg PD, Carter SD, Innes JF, Mobasheri A, Shakibaei M, Schwab W, Bondy CA Nutraceutical therapies for degenerative joint diseases: a critical review. Crit Rev Food Sci Nutr. 2005;45(3):145-64.

23. Kwon YB, Lee HJ, Han HJ, Mar WC, Kang SK, Yoon OB, Beitz AJ, Lee JH. The water-soluble fraction of bee venom produces antinociceptive and anti-inflammatory effects on rheumatoid arthritis in rats. Life Sci. 2002;71(2):191-204.

24. Kim HW, Kwon YB, Ham TW, Roh DH, Yoon SY, Kang SY, Yang IS, Han HJ, Lee HJ, Beitz AJ, Lee JH. General pharmacological profiles of bee venom and its water soluble fractions in rodent models. J Vet Sci. 2004;5(4):309-18.

25. Park HJ, Lee SH, Son DJ, Oh KW, Kim KH, Song HS, Kim GJ, Oh GT, Yoon DY, Hong JT. Antiarthritic effect of bee venom: inhibition of inflammation mediator generation by suppression of NF-kappaB through interaction with the p50 subunit. Arthritis Rheum. 2004;50(11):3504-15.

26. Severino MG, Cortellini $G$, Bonadonna $P$, Francescato $E$, Panzini I, Macchia D, Campi P, Spadolini I, Canonica WG, Passalacqua G. Sublingual immunotherapy for large local reactions caused by honeybee sting: a double-blind, placebocontrolled trial. J Allergy Clin Immunol. 2008;122(1):44-8.

27. Park S, Chun HJ, Keum B, Seo YS, Kim YS, Jeen YT, Lee HS, Um SH, Kim CD, Ryu HS. Anaphylactic shock-induced ischemic proctocolitis following bee stings: first case report. Endoscopy. 2010; 42(Suppl 2): E153-E154.

28. Prado M, Solano-Trejos G, Lomonte B. Acute physiopathological effects of honeybee (Apis mellifera) envenoming by subcutaneous route in a mouse model. Toxicon. 2010; 56: 1007-1017.

29. Lee JD, Park HJ, Chae Y, Lim S. An Overview of Bee Venom Acupuncture in the Treatment of Arthritis. Evid Based Complement Alternat Med. 2005;2(1):79-84.

30. Schumacher MJ, Schmidt JO, Egen NB. Lethality of 'killer' bee stings. Nature. 1989;337(6206):413.

31. Schumacher MJ, Schmidt JO, Egen NB, Lowry JE. Quantity, analysis, and lethality of European and Africanized honey bee venoms. Am J Trop Med Hyg. 1990;43(1):79-86. 